\title{
Tris (trimethylsilyl) Phosphate as Electrolyte Additive for Lithium - Ion Batteries with Graphite Anode at Elevated Temperature
}

\author{
Yaojian Ren, Mingzhen Wang, Jiali Wang, Yongli Cui ${ }^{*}$
}

School of Materials Science and Engineering, China University of Mining \& Technology, Xuzhou 221116, China

*E-mail: lilyshuoxu@163.com

doi: $10.20964 / 2018.01 .61$

Received: 15 February 2017 / Accepted: 2 November 2017 / Published: 16 December 2017

In this work, the tris(trimethylsilyl) phosphite (TMSP) was used as an electrolyte additive to improve the cycling performance of graphite anode at elevated temperature $\left(60^{\circ} \mathrm{C}\right)$. The electrochemical properties were characterized by $\mathrm{CV}$, galvanostatic cycling and EIS. The $\mathrm{CV}$ and galvanostatic cycling results showed as the concentration of TMSP added in the electrolyte was 5 vol. \%, the graphite had good cycle stability to reach $332.27 \mathrm{mAh} / \mathrm{g}$ at $60^{\circ} \mathrm{C}$, with a capacity retention of $96.1 \%$ after 70 cycles. SEM and EIS revealed that the TMSP additives effectively suppress the electrolyte decomposition and stabilized the SEI of the graphite at elevated temperature. In addition, the TMSP can drastically decrease the resistances of SEI and charge transfer at elevated temperature.

Keywords: lithium ion battery, electrolyte additive, tris(trimethylsilyl) phosphite, cycling performance, Electrochemical impedance spectroscopy

\section{FULL TEXT}

(C) 2018 The Authors. Published by ESG (www.electrochemsci.org). This article is an open access article distributed under the terms and conditions of the Creative Commons Attribution license (http://creativecommons.org/licenses/by/4.0/). 